\title{
PENGARUH METODE PEMBELAJARAN TERHADAP DISPOSISI MATEMATIKA DAN PEMAHAMAN MATEMATIKA
}

\author{
Ufiya Putri Adhiyati \\ Universitas Indraprasta PGRI Jakarta, Indonesia \\ ufhiya@yahoo.com
}

\begin{abstract}
Received: 10 September 2020 Tujuan dari penelitian untuk mendapatkan informasi tentang pengaruh Revised: 15 September 2020 metode pembelajaran terhadap disposisi matematika dan pemahaman Accepted: 16 September 2020 matematika secara multivariat, untuk mengetahui pengaruh metode pembelajaran terhadap disposisi matematika dan untuk mengetahui pengaruh metode pembelajaran terhadap pemahaman matematika. Dalam penelitian ini, penulis menggunakan Eksperimen dengan statistik Manova dan dilaksanakan di SMPI yang terletak di daerah kecamatan Bantargebang Bekasi. Hasil penelitian menyimpulkan bahwa terdapat pengaruh sangat relevan metode pembelajaran terhadap disposisi matematika dan pemahaman matematika secara multivariat, hal ini dikuatkan dengan perolehan nilai sig $=0,000<0,05$ dengan $F$ hitung $=20,773$, terdapat pengaruh sangat relevan metode pembelajaran terhadap disposisi matematika yang dikuatkan dengan perolehan nilai sig $=$ $0,000<0,05$ dengan $F$ hitung $=19,250$ dan terdapat pengaruh sangat relevan metode pembelajaran terhadap pemahaman matematika yang dikuatkan dengan perolehan nilai sig $=0,000<0,05$ dengan $F$ hitung $=$ 15,362. Untuk meningkatkan disposisi matematika dan pemahaman matematika, yaitu dengan melibatkan proses pengoptimalan siswa dalam memulai pelajaran dengan menumbuhkan motivasi terlebih dahulu agar siswa semangat memahami pelajaran matematika serta dituntut keaktifan dalam mengkonstruksi pengetahuannya sendiri sehingga siswa lebih mengerti dengan materi pembelajaran dan proses pembelajaran lebih menyenangkan dan nyaman.
\end{abstract}

Keywords: Metode Pembelajaran; Accelerated Learning; NHT; Disposisi Matematika; Pemahaman Matematika

(*) Corresponding Author: $\quad$ Adhiyati, ufhiya@yahoo.com, 082260825370

How to Cite: Adhiyati, U. P. (2020). Pengaruh Metode Pembelajaran Terhadap Disposisi Matematika Dan Pemahaman Matematika. Research and Development Journal of Education, 1(1), 81-90.

\section{INTRODUCTION}

Dalam lingkup pendidikan sekolah, matematika termasuk salah satu pelajaran wajib diikuti oleh siswa. Matematika merupakan sumber dan landasan dari semua mata pelajaran lainnya. Pendidikan matematika mengarahkan anak didik mencapai kompetensi matematika yang diharapkan. Menurut Kilpatrick, Swafoord, dan Findell (2006: 5), ada lima kompetensi matematika atau kemampuan matematika (mathematical proficiency) yang seharusnya dapat dicapai oleh siswa melalui pembelajaran matematika, yaitu: 1) Pemahaman konsep (Conceptual understanding); 2) Pemahaman prosedur (Procedural fluency); 3) Kemampuan strategis (Strategic competence); 4) Penalaran adaptif (Adaptif reasoning); dan 5) Disposisi yang produktif (Productive disposition). Pada komponen matematika tersebut terdapat 4 komponen ranah kognitif. Komponen tersebut yaitu 
pemahaman konsep, pemahaman prosedur, kemampuan strategis dan penalaran adaftif dan 1 komponen ranah afektif yaitu disposisi yang produktif (productive disposition).

Menurut Kilpatrick, Swafoord, \& Findell (2006:131), Disposisi yang produktif ditimbulkan dari tumbuhnya sikap positif dan kebiasaan untuk melihat matematika sebagai suatu yang logis, berguna dan berfaedah. Disposisi matematik merupakan faktor yang mempengaruhi siswa untuk belajar matematika. Pembelajaran matematika tidak hanya didominasi oleh aspek kognitif saja, tetapi harus seimbang antara ranah dalam kognitif, ranah dalam afektif, serta ranah dalam psikomotor. Tujuan pembelajaran matematika yang terdapat dalam kurikulum 2006 mencakup aspek kognitif yaitu kemampuan pemahaman matematik yang didukung dengan aspek afektif yaitu mengembangkan disposisi matematika. Disposisi matematik berpengaruh penting untuk membangun dan mendorong jalannya aspek kognitif, yang dimulai dengan rasa minat, keingintahuan, dan kecenderungan untuk melihat manfaat dari belajar matematika.

Setelah siswa mulai mempunyai rasa disposisi matematik yang kuat, siswa akan mulai cepat mengerti dan paham tentang apa yang dipelajari dalam materi matematika. Kemampuan pemahaman matematik siswa dan disposisi matematik yang dimiliki siswa sangat berkaitan dan saling mendukung satu sama lain. Siswa memerlukan disposisi matematik agar bisa bertahan menyikapi masalah, mempunyai tanggung jawab penuh untuk belajar, dan memiliki kemauan keras dalam belajar matematika. Sifat tersebut sangatlah penting dalam diri siswa. Kelak, nantinya siswa tidak akan menerapkan semua ilmu yang dia dapatkan di sekolah, tetapi dengan adanya sikap disposisi yang kuat dalam dirinya akan siap menghadapi berbagai macam masalah dalam kehidupannya. Salah satu pembelajaran yang bisa mengembangkan disposisi matematik siswa dan kemampuan pemahaman matematik siswa adalah pembelajaran dengan metode Accelerated Learning (AL). Dilihat dari tahapan dalam pembelajaran ini melibatkan proses pengoptimalan siswa dalam memulai pelajaran dengan menumbuhkan motivasi terlebih dahulu agar siswa semangat untuk belajar dan dituntut keaktifan siswa dalam mengkonstruksi pengetahuan-pengetahuannya sendiri sehingga siswa lebih mengerti dengan materi pembelajaran dan proses pembelajaran lebih menyenangkan, nyaman dan cepat.

Selain itu terdapat metode pembelajaran kooperatif dengan Number Heads Together (NHT). Metode pembelajaran ini dibuat agar siswa terlibat langsung untuk memahami secara keseluruhan materi pembelajaran dan guru bisa mengevaluasi sejauh mana pemahaman siswa dalam menangkap materi pembelajaran. Metode NHT dikhususkan untuk keaktifan siswa dalam menemukan informasi, menangkap dan mengolah informasi sehingga bisa dievaluasi dengan cara mempresentasikan hasilnya di dalam kelas Dengan demikian, penulis tertarik untuk meneliti masalah tersebut dengan mengajukan judul yaitu "Pengaruh Metode Pembelajaran terhadap Disposisi Matematika dan Pemahaman Matematika".

Berdasarkan paparan diatas akhirnya peneliti merumuskan masalah yaitu : 1) Apakah terdapat pengaruh metode pembelajaran terhadap disposisi matematika dan pemahaman matematika secara multivariat, siswa SMPI di daerah sekolah kecamatan di Bantargebang Bekasi? 2) Apakah terdapat pengaruh metode pembelajaran terhadap disposisi matematika, siswa SMPI di daerah sekolah kecamatan di Bantargebang Bekasi? 3) Apakah terdapat pengaruh metode pembelajaran terhadap pemahaman matematika, siswa SMPI di daerah sekolah kecamatan di Bantargebang Bekasi? 


\section{LITERATURE REVIEW}

\section{Disposisi Matematika}

Menurut Sumarmo (2013:129) disposisi matematika memiliki keinginan, kesadaran, serta dedikasi yang kuat dalam diri siswa untuk mempelajari matematika dan melakukan berbagai macam kegiatan dalam hal bidang matematika. Keinginan untuk mengerjakan tugas matematika, keinginan untuk memecahkan permasalahan matematika, keinginan untuk mengkomunikasikan ide-ide matematika, dan kesadaran untuk belajar matematika merupakan hal yang sangat penting juga bermanfaat. Katz (2009 :25) menjelaskan disposisi adalah pembiasaan untuk melakukan kegiatan dengan teratur, sadar, dan sukarela agar mendapatkan tujuan yang diinginkan. Perilaku tersebut dicirikan dengan adanya sikap percaya diri yang kuat untuk belajar matematika. Perilaku lain juga diiringi dengan mempunyai rasa keingintahuan untuk memecahkan masalah matematika, teliti dalam mengerjakan masalah matematika, mau bekerjasama dengan temannya apabila ada masalah yang sulit, menghargai perbedaan pendapat temannya, dan menyukai pelajaran matematika.

Untuk memiliki kecenderungan belajar matematika dan bertindak positif dalam belajar matematika, maka siswa harus membiasakan kegiatan yang positif dalam kehidupan sehari-hari. Jika siswa terbiasa melakukan kebiasaan yang baik seperti kebiasaan dalam menyelesaikan permasalahan matematika dan kebiasaan untuk berpikir secara matematika, maka siswa akan terbiasa memiliki kecenderungan untuk belajar matematika. Costa dan Kallick (2012:18-39) mengungkapkan kecenderungan sikap tersebut dinamai dengan habit of mind atau disebut kebiasaan berpikir. Disposisi matematika didasari dengan minat yang tulus untuk mempelajari matematika, adanya rasa ketekunan untuk mencari solusi masalah, kemauan untuk menemukan solusi dan pemecahan masalah dengan strategi yang mudah untuk bisa dipahami serta dapat mengkaitkan matematika dengan kehidupan sehari-hari dan dengan bidang lainnya seperti seni, akutansi, geografi, ekonomi, arsitektur, demografi, atau teknologi. Disposisi matematika siswa diwujudkan dalam cara mereka mendekati tugas apakah dengan keyakinan, kemauan untuk mengeksplorasi alternatif, ketekunan, minat dan kecenderungan mereka dalam merefleksikan ide mereka, (NCTM, 2006: 10)

Perkins, Jay, and Tishman ( 2009: 3) mengemukakan bahwa konsep disposisi diperluas dengan "triadic disposisi, "yang menekankan (1) kecenderungan, yang mungkin mencerminkan motivasi, kebiasaan, kebijakan, atau faktor lain, (2) kepekaan terhadap kesempatan, dan (3) kemampuan sendiri. Dengan didasari oleh keyakinan dirinya dalam menghadapi permasalahan matematika. Syaban (2009:129) menyimpulkan indikator-indikator disposisi matematika yaitu memperlihatkan kemauan untuk mempelajari matematika, memperlihatkan perhatian khusus untuk mempelajari matematika, memperlihatkan kegigihan untuk menghadapi situasi masalah, memperlihatkan sikap percaya diri untuk mempelajari dan menyelesaikan situasi masalah, memperlihatkan sikap ingin tahu sangat tinggi, serta kemampuan untuk berbagi dengan orang lain. Silver (dalam Sumarmo, 2013:203) menguraikan disposisi matematika yaitu memiliki sikap percaya diri (self confident), sikap kemampuan akan dirinya (self efficacy), sikap ingin tahu (curiousity), suka menyelesaikan tugas pelajaran matematika, rajin dan tekun (diligence), fleksibel (flexibility) serta reflektif.

\section{Pemahaman Matematika}

Menurut Ghani (2016:9), pemahaman merupakan terjemahan dari istilah understanding yang dapat diartikan sebagai penyerapan arti suatu materi yang dipelajari. Salah satu tanda bahwa siswa itu paham yaitu siswa mampu menangkap 
materi yang telah didapatkannya. Kemampuan siswa untuk memahami pelajaran menghasilkan makna bahwa materi-materi yang diajarkan guru bukan sekedar hafalan saja, tetapi siswa lebih mengerti konsep dasar dari materi pelajaran tersebut. Pemahaman matematika adalah tujuan penting untuk belajar matematika agar guru dapat dengan mudah menyampaikan isi materi sehingga mendapatkan tujuan pembelajaran diharapkan.

Didukung pendapat Herbert dan Carpenter (dalam Ranti, 2013:1) mengemukakan bahwa manfaat pengetahuan yang diperoleh dalam pembelajaran matematika dengan kemampuan pemahaman matematik sebagai berikut:

1) generatif, artinya pengetahuan yang terbentuk bisa ditimbulkan kembali dengan cara menstimulus hasil pembelajaran

2) bermakna,artinya materi pembelajaran dengan kemampuan berfikir pada siswa dapat berjalan secara relevan dan bermakna.

3) Memperkuat hapalan dan ingatan

4) Memudahkan keselarasan pemikiran dan pemahaman dalam konteks pengetahuan lama yang diperbaharui dengan pengetahuan baru sehingga dengan cepat dapat diingat kembali pembelajarannya.

5) Mempengaruhi kepercayaan, siswa dapat belajar dengan sistematis dalam fase kognitifnya.

\section{Metode Pembelajaran Accelarated Learning}

Meier (2009:49-50) mengemukakan munculnya konsep Accelerated Learning atau Cara Belajar Cepat (CBC) dicetuskan pertama kali oleh dokter penyakit jiwa asal Bulgaria, Georgi Lozanov. Georgi Lozanov menemukan kasus yaitu menenangkan pasiennya dengan musik barok dan memberikan pasien tersebut sugesti positif dengan kesembuhannya, pada akhirnya banyak pasien mengalami kemajuan sangat pesat. Georgi Lozanov mendapatkan hasil bahwa metode ini dapat pula diterapkan dalam bidang pendidikan. Dibantu pemerintah Bulgaria, Georgi Lozanov mulai melaksanakan penelitian tentang pengaruh musik dan sugesti positif dalam pembelajaran sebagai materinya. Georgi Lozanov menyimpulkan bahwa kombinasi antara musik, sugesti positif, serta permainan anak-anak dapat dirasakan pelajar untuk belajar jauh lebih efektif dan cepat dipahami. Semenjak itu Accelerated Learning mulai dikembangkan oleh tokoh-tokoh ahli ilmuan terkemuka.

Sejalan dengan pendapat Rose dan Nichols (2007:38), CBC adalah unsur pokok pekerjaan berpuluh-puluh tahun, yang memecahkan berbagai penelitian rintisan. Dimulai dari penelitian dokter penyakit jiwa pendidikan Bulgaria, Georgi Lozanov hingga penelitian di Harvard yang dilakukan seorang pendidik yaitu Howard Gardner. Penelitian ini mendeskripsikan ilmu-ilmu dari para penerima gelar hadiah Nobel seperti yang terjadi oleh para ilmuan saraf yaitu Roger Sperry dan ilmuan biologi saraf Gerald Edelman.

\section{Metode Pembelajaran Numbered Head Together (NHT)}

Metode pembelajaran kooperatif model NHT ini adalah proses pembelajaran dimana guru mengelompokan siswa secara heterogen sesuai dengan tingkat kemampuan siswa. Pembelajaran disini melalui kelompok, tiap kelompok bekerjasama untuk berdiskusi memecahkan masalah yang dihadapi. Selain itu senada dengan Solihatin, "Metode pembelajaran kooperatif diyakini dapat membuat aktif siswa untuk terlibat dalam forum diskusi, berani untuk mengemukakan pendapat, berpikir secara kritis, dan bertanggung jawab atas dirinya sendiri" (Daryanto, 2011:401). Metode pembelajaran kooperatif juga berfungsi untuk mengasah kemampuan berpikir, 
bekerjasama, berdiskusi, berani dan memupuk tanggung jawab anggota kelompok untuk memberikan pendapatnya.

Pembelajaran kooperatif juga menurut Kagen dalam Suhartini (2010: 41), "dengan mengaktifkan siswa untuk mencerna materi dalam pelajaran dan mengetahui sejauh mana pemahaman siswa akan materi tersebut. Cara tersebut bisa menghasilkan jaminan bahwa siswa dapat terjun langsung dalam pembelajaran dan sangat penting meningkatkan rasa tanggung jawab siswa dalam kelompok". Jadi, pembelajaran kooperatif untuk mengetahui sejauh mana pemahaman pada siswa terkait isi pelajaran tersebut, memastikan siswa terlibat langsung dan mempunyai rasa tanggung jawab penuh bekerjasama dalam kelompok.

\section{METHODS}

Penelitian ini menggunakan eksperimen dengan Analisis Multivariat (Manova Satu Arah). Populasi penelitian ini adalah seluruh siswa-siswi kelas VII di SMPIT Arrahman Islamic School dan SMPI Nurul Huda. Sampel penelitian adalah siswa kelas VII SMPI di daerah sekolah Kecamatan di Bantargebang Kota Bekasi dengan jumlah siswa sebanyak 30 siswa terdiri dari kelas VII B 30 siswa SMPIT Arrahman Islamic School sebagai kelas eksperimen, serta kelas VII A 30 siswa SMPI Nurul Huda sebagai kelas kontrol. Teknik pengumpulan data penelitian ini dengan pemberian evaluasi melalui tes tertulis bentuk soal berupa uraian kepada siswa kelas VII B SMPIT Arrahman Islamic School dan VII A SMPI Nurul Huda sebagai sampel penelitian, dengan lembar instrument tes materi Segi Empat. Pengumpulan data tentang disposisi matematika dengan angket yang akan diberikan pada semua siswa setiap peneliti melakukan treatment. Angket ini menerangkan tentang pernyataan-pernyataan mengenai disposisi matematik siswa. Angket dalam penelitian ini dibuat berdasarkan skala disposisi matematika antara lain dapat disusun dalam bentuk skala menggunakan Likert yang terdapat serangkaian pernyataan positif dan negatif berkenaan dengan aspek disposisi yang akan diukur. Analisis data penelitian ini menggunakan uji normalitas univariat dan multivariat; uji homogenitas varian, matriks varian dan matrik kovarian; serta uji hipotesis penelitian

\section{RESULTS \& DISCUSSION}

\section{Results}

1. Hasil Perhitungan

Tabel 1.

Skor Disposisi Matematika dan Pemahaman Matematika

\begin{tabular}{cccc}
\hline \multicolumn{2}{c}{$\mathbf{A}_{\mathbf{1}}$} & \multicolumn{3}{c}{$\mathbf{A}_{\mathbf{2}}$} \\
\multicolumn{2}{c}{\begin{tabular}{c} 
Accelerated Learning \\
\multicolumn{1}{c}{$\mathbf{Y}_{\mathbf{1}}$}
\end{tabular}} & $\mathbf{Y}_{\mathbf{2}}$ & \multicolumn{2}{c}{ Numbered Heads Together } \\
\hline $\mathrm{n}=30$ & $\mathrm{n}=30$ & $\mathrm{n}=30$ & $\mathbf{Y}_{\mathbf{1}}$ \\
$\bar{X}=85,37$ & $\bar{X}=89,33$ & $\bar{X}=79,57$ & $\bar{X}=30$ \\
Sd $=5,041$ & Sd $=6,155$ & $\mathrm{Sd}=5,224$ & $\mathrm{Sd}=6,425$ \\
\hline \multicolumn{2}{l}{ Sumber : Data diolah }
\end{tabular}


a. Data Disposisi Matematika Pada Pembelajaran Accelerated Learning Disposisi Matematika pada 30 orang siswa yang diberikan metode pembelajaran Accelerated Learning memiliki skor teoritik 0-100 \% dengan skor terendah $80 \%$, skor tertinggi $100 \%$. Disposisi matematika siswa dalam kelompok ini mempunyai skor rata-rata 85,37 dan standar deviasi 5,014.

b. Data Disposisi Matematika Pada Metode Numbered Heads Together Disposisi Matematika pada 30 orang siswa yang diberikan metode kooperatif NHT memiliki skor teoritik 0-100\% dengan skor terendah $75 \%$, skor tertinggi $93 \%$. Disposisi matematika siswa dalam kelompok ini mempunyai skor rata-rata 79,57 dan standar deviasi 5,224.

c. Data Pemahaman Matematika Pada Metode Pembelajaran Accelerated Learning

Pemahaman matematika pada 30 orang siswa yang diberikan metode pembelajaran Accelerated Learning memiliki skor teoritik 0-100 dengan skor terendah 80 , skor tertinggi 100 . Kemampuan pemahaman matematika siswa dalam kelompok ini mempunyai skor rata-rata 89,33 dan standar deviasi 6,155.

d. Data Pemahaman Matematika Pada Metode Numbered Heads Together Pemahaman matematika pada 30 orang siswa yang diberikan metode kooperatif NHT memiliki skor teoritik 0-100 dengan skor terendah 73, skor tertinggi 97. Pemahaman matematika siswa dalam kelompok ini mempunyai skor rata-rata 82,97 dan standar deviasi 6,425.

2. Pengujian Persyaratan Analisis

a. Uji Normalitas Data

Tabel 2.

Perhitungan pada Hasil Uji Normalitas Data

\begin{tabular}{llcccc}
\hline & & $\begin{array}{c}\text { One-Sample Kolmogorov-Smirnov Test } \\
\text { Disposisi Mat } \\
\text { dengan } \\
\text { Metode AL }\end{array}$ & $\begin{array}{c}\text { Disposisi Mat } \\
\text { dengan Metode } \\
\text { NHT }\end{array}$ & $\begin{array}{c}\text { Pemahaman } \\
\text { Mat dengan } \\
\text { Metode AL }\end{array}$ & $\begin{array}{c}\text { Pemahaman Mat } \\
\text { dengan Metode } \\
\text { NHT }\end{array}$ \\
\hline \multicolumn{1}{c}{ N } & Mean & 85.37 & 30 & 30 & 30 \\
Normal & Std. & 5.014 & 79.57 & 89.33 & 82.97 \\
Parameters & Deviation & .241 & .224 & 6.155 & 6.425 \\
Most & Absolute & .241 & .222 & .142 & .145 \\
Extreme & Positive & .241 & .140 & .145 \\
Differences & Negative & -.151 & -.191 & -.142 & -.097 \\
Kolmogorov & Smirnov & 1.319 & 1.215 & .780 & .792 \\
Z & & $\mathbf{. 0 6 2}$ & $\mathbf{. 1 0 5}$ & $\mathbf{. 5 7 6}$ & $\mathbf{. 5 5 8}$ \\
Asymp. Sig.(2-tailed) & & & &
\end{tabular}

Sumber : Data diolah

b. Pengujian Homogenitas

Tabel 3.

Pengujian tentang Kesetaraan Matriks Kovarian

\begin{tabular}{cc}
\hline Pengujian tentang Kesetaraan Matriks Kovarian \\
\hline Box's M & .119 \\
F & .038 \\
\hline
\end{tabular}




\begin{tabular}{cc}
\hline df1 & 3 \\
df2 & 605520.000 \\
Sig. & .990 \\
\hline
\end{tabular}

Sumber : Data diolah

Tabel 4.

Pengujian Kesetaraan Varians

\begin{tabular}{ccccc}
\hline & F & df1 & df2 & Sig. \\
\hline Disposisi Matematika & .834 & 1 & 58 & .365 \\
$\begin{array}{c}\text { Kemampuan Pemahaman } \\
\text { Matematika }\end{array}$ & .026 & 1 & 58 & .872 \\
\hline Sumber: Duta diolah & & &
\end{tabular}

Sumber : Data diolah

c. Pengujian Hipotesis Penelitian

Tabel 5.

Multivariate Tests

\begin{tabular}{|c|c|c|c|c|c|c|}
\hline & \multicolumn{6}{|c|}{ Multivariate Tests } \\
\hline & Effect & Value & $\mathbf{F}$ & Hypothesis df & Error df & Sig. \\
\hline \multirow{4}{*}{ Intercept } & Pillai's Trace & .998 & 16078.173 & 2.000 & 57.000 & .000 \\
\hline & $\begin{array}{c}\text { Wilks' } \\
\text { Lambda }\end{array}$ & .002 & 16078.173 & 2.000 & 57.000 & .000 \\
\hline & $\begin{array}{l}\text { Hotelling's } \\
\text { Trace }\end{array}$ & 564.146 & 16078.173 & 2.000 & 57.000 & .000 \\
\hline & $\begin{array}{c}\text { Roy's Largest } \\
\text { Root }\end{array}$ & 564.146 & 16078.173 & 2.000 & 57.000 & .000 \\
\hline \multirow{4}{*}{ A } & Pillai's Trace & .422 & 20.773 & 2.000 & 57.000 & .000 \\
\hline & $\begin{array}{l}\text { Wilks' } \\
\text { Lambda }\end{array}$ & .578 & 20.773 & 2.000 & 57.000 & .000 \\
\hline & $\begin{array}{l}\text { Hotelling's } \\
\text { Trace }\end{array}$ & .729 & 20.773 & 2.000 & 57.000 & .000 \\
\hline & $\begin{array}{c}\text { Roy's Largest } \\
\text { Root }\end{array}$ & .729 & 20.773 & 2.000 & 57.000 & .000 \\
\hline
\end{tabular}

Sumber : Data diolah

Tabel 6.

Tests of Between-Subjects Effects

\begin{tabular}{|c|c|c|c|c|c|}
\hline Source & $\begin{array}{l}\text { Dependent } \\
\text { Variable }\end{array}$ & $\begin{array}{l}\text { Tipe } 3 \text { jumlah } f \\
\text { Square }\end{array}$ & $\begin{array}{l}\text { Rata- } \\
\text { rata } \\
\text { Square }\end{array}$ & $\mathbf{F}$ & Sig. \\
\hline \multirow{3}{*}{$\begin{array}{l}\text { Corrected } \\
\text { Model }\end{array}$} & $\begin{array}{l}\text { Disposisi } \\
\text { Matematika }\end{array}$ & 504.600 & 504.600 & 19.250 & 000 \\
\hline & Kemampuan & & & & \\
\hline & $\begin{array}{l}\text { Pemahaman } \\
\text { Matematika }\end{array}$ & 608.017 & 608.017 & 15.362 & 000 \\
\hline \multirow[b]{2}{*}{ Intercept } & $\begin{array}{l}\text { Disposisi } \\
\text { Matematika }\end{array}$ & 408045.067 & $\begin{array}{c}408045 . \\
067\end{array}$ & $\begin{array}{c}15566.7 \\
27\end{array}$ & 000 \\
\hline & $\begin{array}{l}\text { Kemampuan } \\
\text { Pemahaman } \\
\text { Matematika }\end{array}$ & 445309.350 & $\begin{array}{r}445309 \\
350\end{array}$ & $\begin{array}{r}11250.9 \\
01\end{array}$ & 000 \\
\hline
\end{tabular}




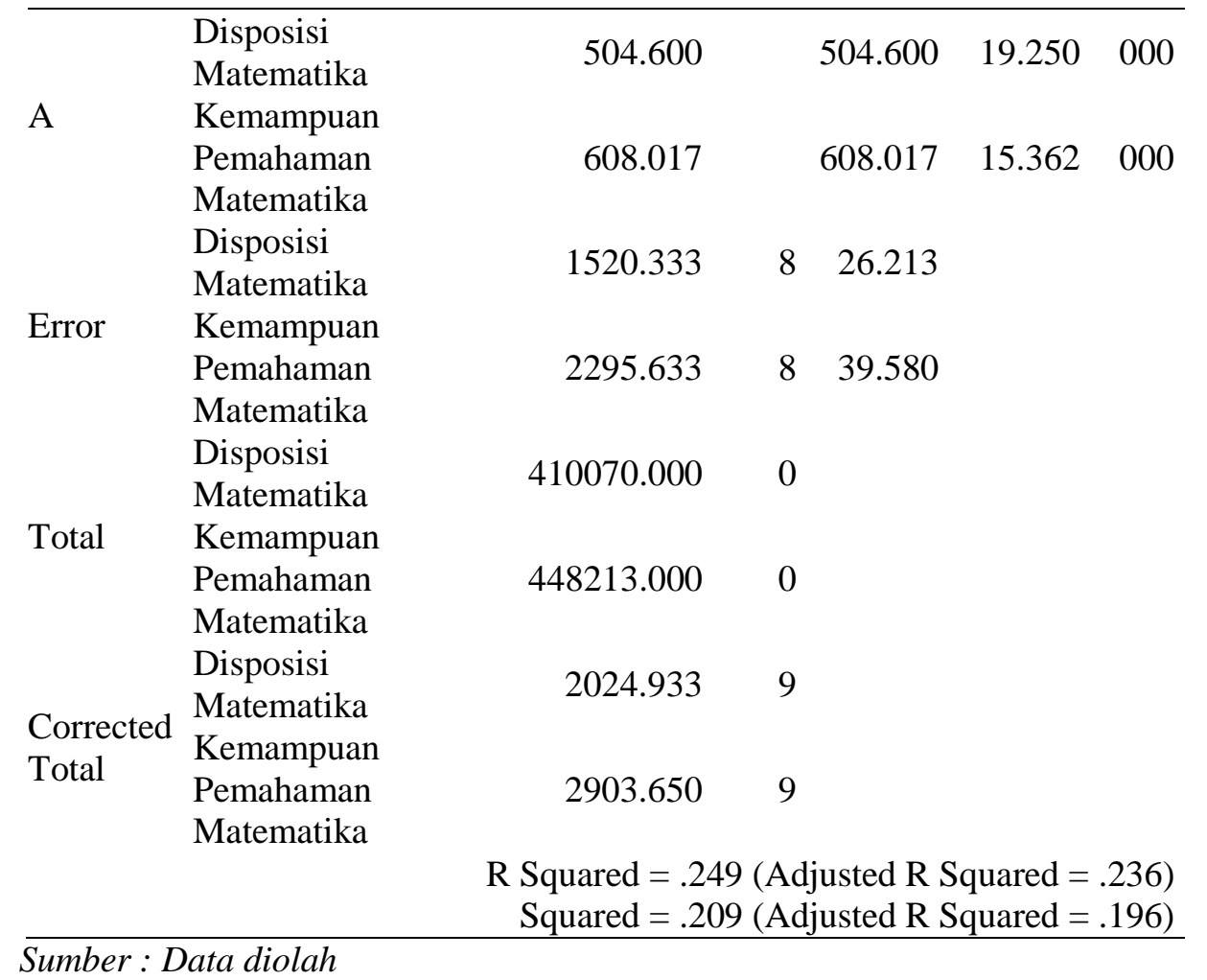

\section{Discussion}

1. Pengaruh Metode Pembelajaran Terhadap Disposisi Matematika dan Pemahaman Matematika Secara Multivariat

Berdasarkan hasil pengujian yang terdapat pada table Multivariate Test pada uji statistik terdapat nilai $\mathrm{F}=20.773$, nilai sig sebesar $0,000<0,05$. Hal ini menunjukkan terdapat pengaruh yang sangat relevan antara metode pembelajaran Accelerated Learning (AL) dan metode kooperatif Numbered Heads Together (NHT) terhadap disposisi matematika dan pemahaman matematika siswa. Dalam hal ini disposisi matematika dan pemahaman matematika menggunakan suatu metode Accelerated Learning pada kelompok eksperimen lebih tinggi daripada menggunakan suatu metode kooperatif Numbered Heads Together pada kelompok kontrol. Hal ini dilihat dari tabel 4.1 rekapitulasi hasil perhitungan skor disposisi matematika dan kemampuan pemahaman matematika menunjukkan bahwa kelompok eksperimen yang menggunakan Accelerated Learning pada nilai $\bar{x}$ atau nilai rata-rata disposisi matematika adalah 85,37 dan nilai rata-rata pemahaman matematika adalah 89,33 sedangkan kelompok control yang menggunakan Numbered Heads Together pada nilai $\bar{x}$ atau nilai rata-rata disposisi matematika adalah 79,57 dan nilai rata-rata pemahaman matematika adalah 82,97. Sehingga dapat dibuktikan bahwa terdapat perbedaan pengaruh metode pembelajaran Accelerated Learning (AL) dan metode kooperatif Numbered Heads Together (NHT) terhadap disposisi matematika dan pemahaman matematika.

2. Pengaruh Metode Pembelajaran Terhadap Disposisi Matematika

Berdasarkan hasil pengujian pada tabel Test of Between-Subject Effects di atas yang merupakan tabel utama yang mempresentasikan hasil hipotesis yang diajukan peneliti. Dari tabel tersebut, diketahui nilai $\mathrm{F}=19.250$, nilai $\mathrm{p}$-value untuk kategori disposisi matematika (Y1) adalah 0,000 lebih kecil dari 0,05 . Dengan demikian $H_{0}$ 
ditolak atau disimpulkan bahwa adanya perbedaan sangat relevan antara disposisi matematika pada kelompok siswa yang diberi metode pembelajaran Accelerated Learning dengan disposisi matematika pada siswa yang diberi metode kooperatif Numbered Heads Together. Sehingga disimpulkan terdapat perbedaan pengaruh sangat relevan metode pembelajaran Accelerated Learning dan metode kooperatif Numbered Heads Together pada disposisi matematika.

3. Pengaruh Metode Pembelajaran Terhadap Pemahaman Matematika

Berdasarkan hasil pengujian pada tabel Tests of Between-Subject Effects diketahui untuk kategori pemahaman matematika (Y2) memperoleh nilai sebesar F yaitu 15.362, dengan nilai sig 0,000 lebih kecil 0,05 . Dengan demikian $H_{0}$ ditolak atau terdapat perbedaan sangat relevan antara pemahaman matematika pada kelompok yang diberi metode pembelajaran Accelerated Learning dengan pemahaman matematika pada kelompok siswa yang diberi metode kooperatif pada Numbered Heads Together. Sehingga disimpulkan terdapat perbedaan pengaruh signifikan metode pembelajaran terhadap pemahaman matematika.

\section{CONCLUSION}

Berdasarkan hasil penelitian maka dapat disimpulkan bahwa:

1. Didapatkan hasil yaitu adanya pengaruh sangat relevan metode pembelajaran terhadap disposisi matematika dan pemahaman matematika secara multivariat, siswa SMPI di daerah sekolah kecamatan di Bantargebang Bekasi. Dikuatkan dengan perolehan nilai sebesar sig yaitu 0,000 lebih kecil 0,05 dengan $\mathrm{F}$ hitung $=20,773$.

2. Terdapat pengaruh sangat relevan metode pembelajaran terhadap disposisi matematika, siswa SMPI di daerah sekolah kecamatan di Bantargebang Bekasi. Dikuatkan dengan perolehan nilai sebesar sig yaitu 0,000 lebih kecil 0,05 dengan $F$ hitung $=19,250$.

3. Terdapat pengaruh sangat relevan metode pembelajaran terhadap pemahaman matematika, siswa SMPI di daerah sekolah kecamatan di Bantargebang Bekasi. Dikuatkan dengan perolehan nilai sebesar sig yaitu 0,000 lebih kecil 0,05 dengan $F$ hitung $=15,362$.

\section{REFERENCES}

Costa, L.A., Kallick, \& Bena. (2012). Belajar dan memimpin dengan 'kebiasaan berpikir'16 karakteristik untuk sukses. Jakarta: PT Indeks.

Daryanto. (2011). Media pembelajaran: peranannya sangat penting dalam mencapai tujuan pembelajaran. Yogyakarta: Gaya Medika.

Ghani, D.A. (2016). Pengaruh penggunaan metode pembelajaran buzz group dalam pembelajaran metamatika terhadap kemampuan pemahaman matematis pada siswa SMA (Tesis). Sekolah Pascasarjana, Universitas Pasundan, Bandung

Katz, \& Lilian. (2009) Dispositions as educational goals, dari (http://www.ericdigest.org/2009/goals.htm)

Kilpatrick, J. (2006). Adding it up:helping children learn mathematics. Washington DC: National Academy.

Meier, D. (2009). The accelerated learning handbook: paduan kreatif \& efektif merancang program pendidikan dan pelatihan. Bandung: Mizan Media Utama. 
NCTM, (2006). Principles and standards for school mathematics. Reston VA: The NCTM.

Perkins. (2009). Beyond abilities: a dispositional theory of thinking. Cambridge: Harvard University.

Rahmawati, R . (2013). Meningkatkan kemampuan pemahaman matematik siswa dengan model pembelajaran investigasi kelompok. Bandung: STKIP Siliwangi .

Rose, C. \& Nichols, J. M. (2010). Accelerated learning for the 21 st century: cara belajar cepat abad xxi. Jakarta: Nuansa.

Suhartini, T. (2010). Penerapan pembelajaran kooperatif tipe numbered head together dalam upaya meningkatkan hasil belajar pada mata pelajaran IPA (PTK terhadap kelas V SDN Mulyasari II Kec Bayongbong Garut). Jurnal Pendidikan Universitas Negeri Garut, 16 (4).

Sumarmo, U. (2013). Kumpulan makalah: berfikir dan disposisi matematik serta pembelajarannya. Bandung: UPI. 